\title{
Sobreproducción de la materia prima (leche) en el altiplano de Bolivia
}

J Selva Andina Anim Sci. 2016; 3(2):57

Por la falta de mercados para acomodar la producción nacional de leche, muchos productores locales están reduciendo significativamente el número de sus vacas lecheras, que están siendo comercializadas como vacuno corriente en ferias o mataderos a un tercio del precio que tenían pocos años atrás.

Actualmente existe una sobreproducción de leche en el departamento de La Paz y cada vez se reduce la demanda de la población, así los agricultores se quedan con el producto teniendo que darle otra finalidad, pero en muchos casos se vuelve inevitable por las grandes cantidades de materia prima, para regular esta crisis, que se ha visto agudizada, por los bajos precios internacionales de este alimento de primera necesidad, situación que estaría impulsando el ingreso de leche y productos procedentes de las países vecinos, de ahí que, es necesario realizar esfuerzos e inversiones para innovar y producir nuevas variedades de artículos lácteos, pue permitan ampliar el mercado, y así competir en mejores condiciones respecto a los productos foráneos.

Sería iniciativas que necesitan apoyo del Estado para su materialización, por ejemplo con dotación de infraestructura industrial, fuentes de energía, exenciones impositivas a la importación de tecnología, mayor flexibilidad fiscal y laboral, facilidades de financiamiento, medidas orientadas a fomentar la producción láctea del país en particular y la industria nacional en general.

El mercado de la leche se ve afectado por la presencia de leche en polvo de contrabando o legalmente importada, situación que un paquete de leche importada en polvo cuesta hasta 20 Bs., mientras que la Planta Industrializadora de Leche (PIL-Andina) comercializa en $41.70 \mathrm{Bs}$.

La leche es un nutrimento fundamental para la salud humana, su aporte en proteínas, calcio y vitaminas es absolutamente importante, sin embargo hay una tendencia muy arraigada, que la leche no le gusta a la población. Esta es una posición falsa, simplemente, las prácticas alimentarias llevan a ese efecto. Desde el vientre materno la leche es imprescindible para el desarrollo de niñas, niños, adultas y adultos, aunque no se crea, la falta de calcio hace que estas personas sufran traumatismos que les haría muy difícil su vida senil. Ahora ¿quién debería consumir leche? ¿Solamente los bebés o niños? Sería antinatural pensar que así debería ser. Todos los seres humanos necesitamos proteínas, calcio y vitaminas. Las podemos aprovechar con el consumo de otros alimentos, pero no siempre es razonable. Los adultos no la consumen porque se privan para entregar a sus hijos e hijas y también por razones culturales, pero la razón económica es prioritaria. En esta sociedad mercantilizada ¿es posible beber leche y yogurt, además de comer queso en las cantidades suficientes?, son preguntas que deben considerarse en estos tiempos.

Apaza-Huallpa Yesenia Universidad Católica Boliviana San Pablo-UCBSP Unidad Académica Campesina Tiahuanaco UAC-T Ingeniería Zootécnica Km 74. Carretera Internacional La Paz-Desaguadero Tel 591-77275391. La Paz, Bolivia E-mail: yesiapazahu040192@gmail.com 